\title{
ULTRASONIC ATTENUATION IN Ni-Pd ALLOYS AT HIGH TEMPERATURE PHASE
}

\author{
R. R. Yadav, A. K. Gupta, D. Singh \\ Physics Department, University of Allahabad, \\ Allahabad-211002, India \\ E-mail: rryadav1@rediffmail.com \\ (Received November 1, 2004)
}

\begin{abstract}
Ultrasonic attenuation coefficients are calculated due to phonon-phonon interaction and thermoelastic mechanism in Ni-Pd alloys at 100-500 K along $\langle 100\rangle$ direction. Second and third order elastic constants (SOEC and TOEC), Grüneisen numbers and ultrasonic velocities are also calculated. The ultrasonic attenuation is determined utilizing these parameters. In the present investigation $\mathrm{Ni}$ and $\mathrm{Pd}$ metals are found stiffer than the Ni-Pd alloys. Behavior of ultrasonic attenuation at high temperatures reveals some disordering in the alloys.
\end{abstract}

Key words: alloys, ultrasonic attenuation, elastic properties, disorder.

PACS number(s): 43.35.Zc; 43.35.Cg; 43.35.Ud; 62.20.Dc

\section{INTRODUCTION}

Ultrasonics offer the possibility to detect and characterize microstructural properties as well as flaws in materials controlling materials behaviour based on physical mechanism to predict future performance of the materials. Various investigators have shown considerable interest on ultrasonic properties of metals and alloys. Behavior of Ultrasonic attenuation, velocity and other related parameters at different physical conditions of the materials are well related to structural inhomogeneties, elastic parameters, dislocation, grains, phase transformation, electrical resistivity, and thermal conductivity [1-4]. Palladium alloys are used in jewelry trades. In view of innumerable applications of palladium alloys in metallurgy, engineering and industry, the authors have choosen to study the behaviour of ultrasonic absorption and related parameters in $\mathrm{Ni}-\mathrm{Pd}$ alloys along $\langle 100\rangle$ direction at high temperatures. Evaluation of ultrasonic absorption and a complete description of the non-linear acoustic properties of the material requires knowledge of all the independent second and third order elastic constants (SOEC and TOEC). Therefore we have calculated second and third order elastic constants of $\mathrm{Ni}-\mathrm{Pd}$ alloys at different temperatures.

\section{THEORETICAL APPROACH}

The total attenuation of an ultrasonic wave propagating in a solid at any temperature can be written as

$$
\alpha_{\text {Total }}=\alpha_{\mathrm{e}-\mathrm{p}}(T)+\alpha_{\mathrm{p}-\mathrm{p}}(T)+\alpha_{\mathrm{bg}}
$$

where $\alpha_{\mathrm{e}-\mathrm{p}}$ is the attenuation resulting from the interaction of wave with the charge carriers in the solid, $\alpha_{\mathrm{p}-\mathrm{p}}$ is the attenuation due to interaction of the acoustic wave with the thermal phonons in the crystal, and $\alpha_{\mathrm{bg}}$ is the background attenuation due to variations in the bonding of the transducer with the crystal, impedance match- ing throughout the measuring system and also diffraction and interference effects. The latter contribution is usually assumed to be temperature independent and this can simply be subtracted from the measured attenuation. It is a well established fact that $\alpha_{\mathrm{e}-\mathrm{p}}$ is important for metals or metallic alloys at low temperatures (less than $100 \mathrm{~K})$. At high temperatures, $\alpha_{\mathrm{p}-\mathrm{p}}$ is the prominent attenuation. We have calculated $\alpha_{\mathrm{p}-\mathrm{p}}$ in $\mathrm{Ni}-\mathrm{Pd}$ alloys at $100-500 \mathrm{~K}$. The mechanism involving the interaction of the thermal phonons and acoustical phonon is the Akhieser mechanism [5]. This mechanism was developed basically for the absorption of the ultrasonic waves in dielectrics and semiconductors. Two modifications of Akhieser's mechanism have been given by Mason [6-7], Woodruff and Ehrenreich [8] for the region $\omega \tau \ll 1$, where $\omega(2 \pi f)$ is the angular frequency of the sound wave and $\tau$ is the relaxation time usually identified with the thermal relaxation time given by,

$$
\tau_{\mathrm{th}}=\frac{3 K}{C_{V} \bar{V}^{2}}
$$

where $K, C_{V}, \bar{V}$ are the thermal conductivity, specific heat per unit volume and the Debye average velocity, respectively. The Mason theory gives the absorption coefficient ' $\alpha$ ' as:

$$
\alpha=\frac{n \omega^{2} D E_{0} \tau}{6 \rho V^{3}}
$$

where $n=2$ for longitudinal waves and $n=1$ for shear waves. $E_{0}$ is the internal energy per unit volume; $\tau$ is the relaxation time, $V$ is the velocity of sound wave, $\rho$ is the density of the material and $D$ is the non-linearity constant defined as:

$$
D=9\left\langle\left(r_{i}^{j}\right)^{2}\right\rangle-\frac{3\left\langle r_{i}^{j}\right\rangle^{2} C_{V} T}{E_{0}}
$$


Here $i, j$ refer to the direction of propagation and polarization of the sound wave. $r_{i}^{j}$ are the generalized Grüneisen parameters. Mason and Bateman also introduced a scheme to calculate $D$ by determining the average of generalized Grüneisen parameters for the number of pure thermal modes for longitudinal and shear waves. Also they relate the Grüneisen parameter with the second order and third order elastic constants.

On the otherhand, Woodruff and Ehrenreich [8] formulated $\alpha$ (in $\mathrm{Np} / \mathrm{m})$ as:

$$
\alpha=\frac{\omega^{2} K T \nu_{a v}^{2}}{\rho V^{5}}
$$

where $T$ is the temperature and $\nu_{a v}$ is the general average Grüneisen parameter originally taken to be an adjustable but temperature independent parameter. Since the product (KT) is nearly constant for a large number of substances over a large range of temperature, Woodruff and Ehrenreich's theory failed to explain the observed temperature dependence of the attenuation in many cases. Nava et al. [9] have modified Akhieser's original theory by introducing a new effective ultrasonic Grüneisen parameter (UGP), which is temperature dependent. Except for this, Nava et al.'s relation for $\alpha$ is very similar to that of Woodruff and Ehrenreich. Nava succeded in to explaining the observed attenuation in the materials as GaAs by his modification. Calculation of UGP involves many complications and many experimental parameters. Although the Mason theory has been criticized by Barrett and Holland [10], the scheme introduced by Mason for averaging the Grüneisen numbers, as mentioned earlier, is still widely used [11]. This scheme directly involves the second and third order elastic constants. Therefore avoiding complications in the calculation of UGP and to calculate temperature dependence of ' $\alpha$ ' directly from the values of second and third order elastic constants (SOEC and TOEC), the Mason theory is still good and established to understand the temperature dependence of ultrasonic attenuation in pure $\mathrm{Ni}$ and $\mathrm{Pd}$ metals $[12,13]$. In the present investigation, this theory is established for the ultrasonic attenuation in $\mathrm{Ni}-\mathrm{Pd}$ alloys at different temperatures. Many of the characteristic features are discussed in this paper.

We have calculated second and third order elastic constants for the evaluation of ultrasonic attenuation in $\mathrm{Ni}-$ Pd alloys using the method developed by Leibfried and Haln, Ludwig, Hiki and Ghate as employed in our previous paper [14].

\section{RESULTS AND DISCUSSION}

The calculated values of second and third order elastic constants of $\mathrm{Ni}-\mathrm{Pd}$ alloys at $100-500 \mathrm{~K}$ are presented in Table 1 . The values of thermal conductivity $(\mathrm{K})$, specific heat per unit volume $\left(C_{V}\right)$, internal energy per unit volume $\left(E_{0}\right)$ and density $(\rho)$ are calculated with the help of the required data available in the literature [15-17]. Temperature variation of the thermal conductivity $(\mathrm{K})$ is shown in Fig. 1. The calculated values of ultrasonic velocities $\left(V_{L}\right)$ for longitudinal waves and $\left(V_{S}\right)$ that for sheer waves along $\langle 100\rangle$ crystallographic direction are shown in Fig. 2. Temperature variation of thermal relaxation time $\left(\tau_{\mathrm{th}}\right)$, non-linearity parameters (acoustic coupling constants) $D_{L}$ and $D_{S}$ for longitudinal and sheer waves, respectively, are shown in Figs. 3-5. Temperature variation of ultrasonic absorption $\left(\alpha / f^{2}\right)$ Akh.Long. and $\left(\alpha / f^{2}\right)$ Akh.Shear in Ni-Pd alloys along $\langle 100\rangle$ direction and $\left(\alpha / f^{2}\right)_{\text {Th. }}$ (attenuation due to thermoelastic loss) are shown in Figs. 6-8. Experimental values of SOEC and TOEC of $\mathrm{Ni}$ at $300 \mathrm{~K}$ and the values of SOEC of $\mathrm{Pd}$ and $\mathrm{Ni}-\mathrm{Pd}$ alloy at $300 \mathrm{~K}$ calculated by previous workers are presented in Table 2. Experimental values of $\left(\alpha / f^{2}\right)$ in $\mathrm{Ni}$ along $\langle 100\rangle$, calculated values of $\left(\alpha / f^{2}\right)_{\mathrm{Akh}}$. and $\left(\alpha / f^{2}\right)_{\text {Th. }}$ in Ni along $\langle 100\rangle$ and calculated values of thermal relaxation time $\left(\tau_{\text {th }}\right)$ for $\mathrm{Ni}$ are presented in Table 3 for comparison.

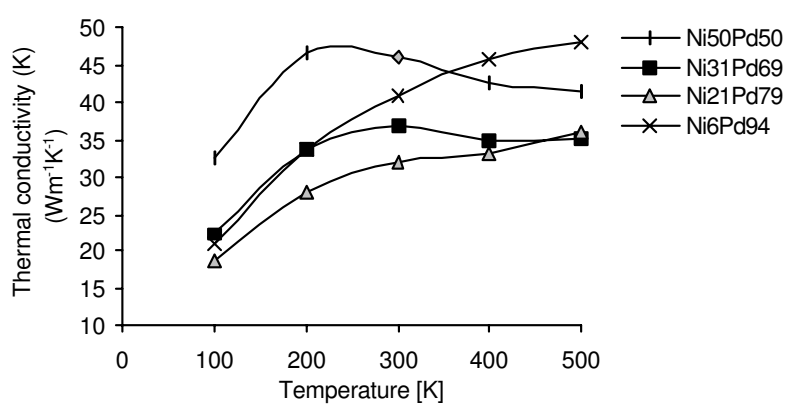

Fig. 1. Thermal conductivity (K) vs. temperature.

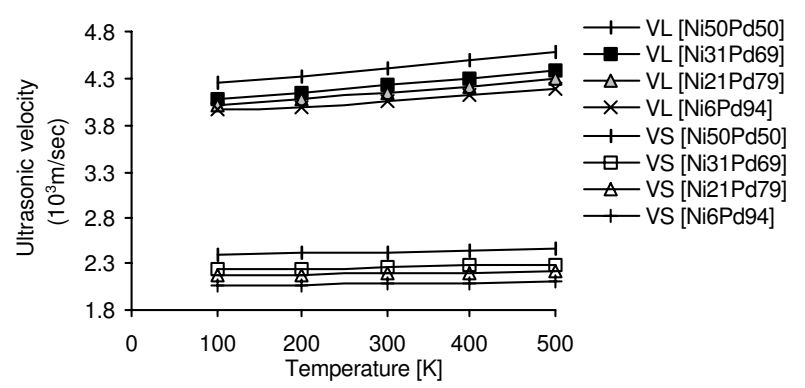

Fig. 2. Ultrasonic velocity $\left(V_{L}\right.$ for long wave $\& V_{S}$ for shear wave.

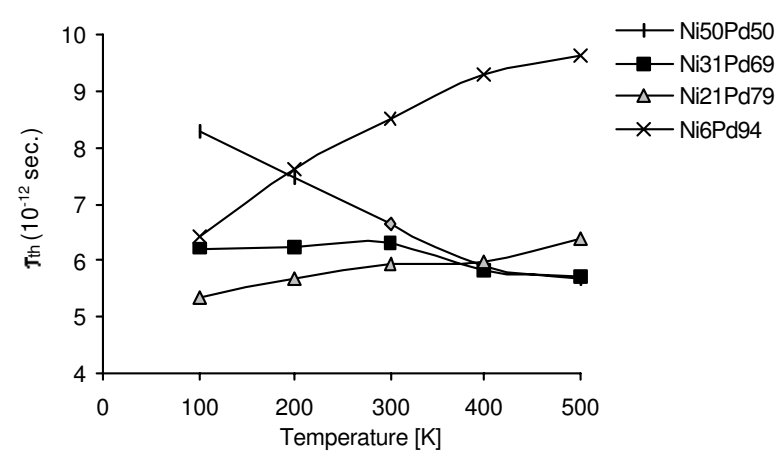

Fig. 3. Thermal relaxation time $\left(\tau_{\text {th }}\right)$ vs. temperature. 
In calculation of SOEC and TOEC, we have taken nearest neighbour distances

$$
\begin{aligned}
& r_{0}\left(\mathrm{Ni}_{50} \mathrm{Pd}_{50}\right)=2.615 \times 10^{-10} \mathrm{~m}, \\
& r_{0}\left(\mathrm{Ni}_{31} \mathrm{Pd}_{69}\right)=2.663 \times 10^{-10} \mathrm{~m}, \\
& r_{0}\left(\mathrm{Ni}_{21} \mathrm{Pd}_{79}\right)=2.688 \times 10^{-10} \mathrm{~m}, \\
& r_{0}\left(\mathrm{Ni}_{6} \mathrm{Pd}_{94}\right)=2.725 \times 10^{-10} \mathrm{~m}
\end{aligned}
$$

for Ni-Pd alloys. Born parameter $b=0.313 \times 10^{-10} \mathrm{~m}$ is taken as constant for each composition of alloys. This Born parameter (hardness parameter) ' $b$ ' satisfies the condition that the total free energy of the alloys in equilibrium should be minimal. It is further assumed that Born parameter is independent of temperature and can be taken empirically $b=0.313 \times 10^{-10} \mathrm{~m}$ nearly equal for all the compositions of alloys.

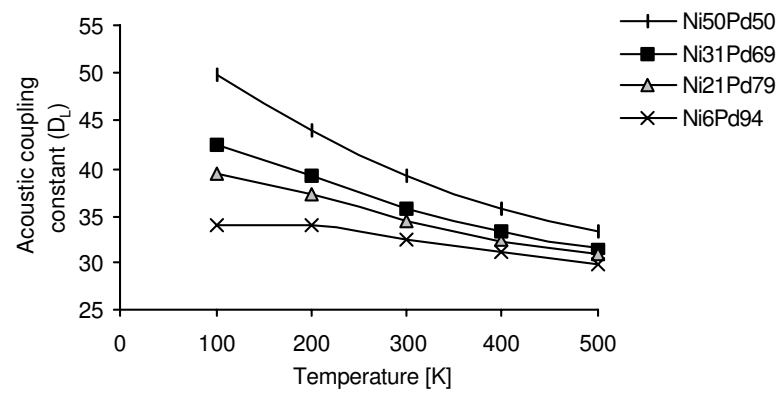

Fig. 4. Acoustic coupling constant ( $D_{L}$ for long wave) vs. temperature.

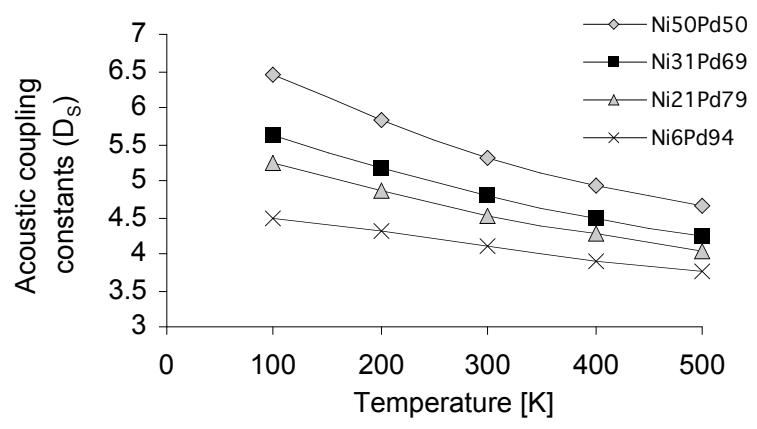

Fig. 5. Acoustic coupling constants ( $D_{S}$ for shear wave) vs. temperature.

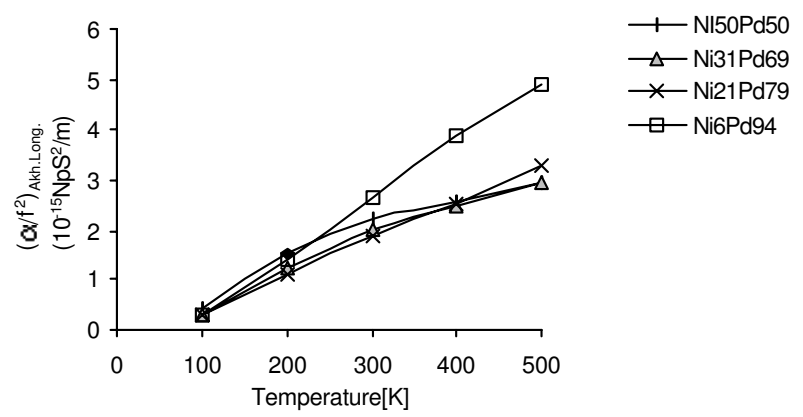

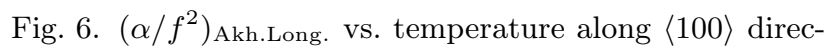
tion.
The present values of elastic constants of $\mathrm{Ni}-\mathrm{Pd}$ alloys are compared with the values calculated by S. C. Upadhyaya [18]. Temperature dependence of SOEC and TOEC of the alloys is not available in literature. Therefore the comparison could be made at $300 \mathrm{~K}$ only. Elastic constants of $\mathrm{Ni}-\mathrm{Pd}$ alloys are also compared with those of pure components calculated by D. K. Hsu and R. G. Leisure [19] and experimentally observed by V. P. N. Sharma and P. J. Reddy [20]. At $300 \mathrm{~K}$ the present values of $C_{11}, C_{12}$ and $C_{44}$ for $\mathrm{Ni}_{50} \mathrm{Pd}_{50}$ are $2.026 \times 10^{11} \mathrm{~N} / \mathrm{m}^{2}, 1.254 \times 10^{11} \mathrm{~N} / \mathrm{m}^{2}$ and $0.611 \times$ $10^{11} \mathrm{~N} / \mathrm{m}^{2}$. S. C. Upadhyaya et al. calculated $C_{11}=$ $2.245 \times 10^{11} \mathrm{~N} / \mathrm{m}^{2}, C_{12}=1.943 \times 10^{11} \mathrm{~N} / \mathrm{m}^{2}$ and $C_{44}=0.748 \times 10^{11} \mathrm{~N} / \mathrm{m}^{2}$ for $\mathrm{Ni}_{0.55} \mathrm{Pd}_{0.45}$ at $300 \mathrm{~K}[18]$. Thus there is good agreement between the present values and the values calculated by S. C. Upadhyaya et al. It is obvious from Tables 1 and 2 that second order elastic constants $\left(C_{i j}\right)$ (experimental and theoretical) of $\mathrm{Ni}$ and $\mathrm{Pd}$ metals are slightly greater than the present values of $\mathrm{Ni}_{50} \mathrm{Pd}_{50}$ alloys at $300 \mathrm{~K}$. Thus the pure components $\mathrm{Ni}$ and $\mathrm{Pd}$ are stiffer than the $\mathrm{Ni}-\mathrm{Pd}$ alloys at high temperatures. The present method of calculation for SOEC and TOEC of Ni-Pd alloys at high temperatures is justified. However, full account of many interactions and van der Waal's interactions between ions and also consideration of the non-linearity of the materials up to some extent may further improve the calculated results of TOEC [21].

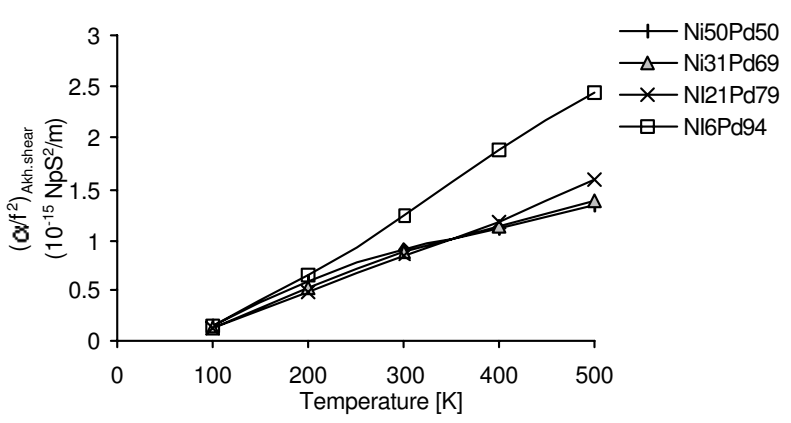

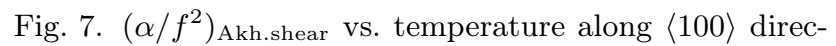
tion.

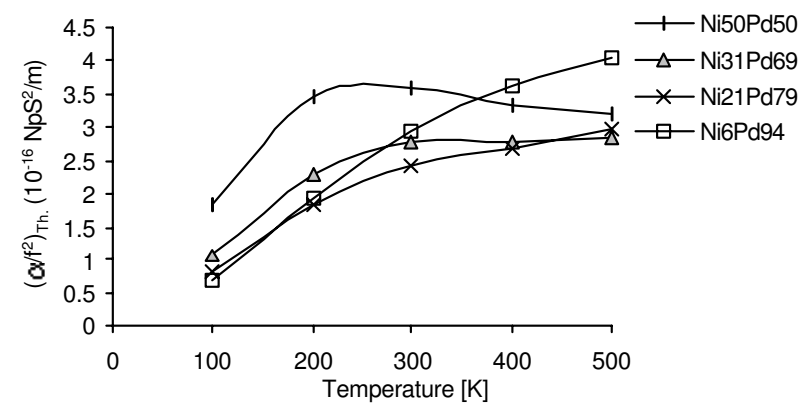

Fig. 8. $\left(\alpha / f^{2}\right)_{\text {Th. }}$ vs. temperature along $\langle 100\rangle$ direction.

Since ordering is normally brought in alloys by the tight binding among unlike neighbours [22]. Therefore, $\mathrm{Ni}-\mathrm{Pd}$ alloys are expected to be stiffer than pure com- 
ponents. But as described above, this behaviour is not found in these compounds. Therefore some disordering is present in the alloying of $\mathrm{Ni}$ and $\mathrm{Pd}$ components. It may be explained as follows. One method of evaluating the structure of conducting materials is to measure the electrical resistivity $(R)$ as a function of temperature. It is a measure of the extent to which electrons are scattered in a lattice as they move through an external electric field. The resistivity originates from perturbations in the movement of electrons produced by the pressure of crystal imperfections. For most metals nearly at room temperature, $R$ depends mainly on the interaction of electrons with phonons. Point defects, such as intertitial atoms and substitutional impurities, are lattice features that contribute to $R$ of a material. At higher temperatures vacancies begin to form in the lattice, and, for ordered alloys, the structure becomes disordered. Therefore the increase in $R$ with temperature corresponds to some disordering in the lattice [23]. The resistivity value of $\mathrm{Ni}-\mathrm{Pd}$ alloys at room temperature is larger than the values of $\mathrm{Ni}$ and $\mathrm{Pd}$ components [15]. Therefore some disordering in the lattice of $\mathrm{Ni}-\mathrm{Pd}$ alloys is present and due to that $\mathrm{Ni}$ and $\mathrm{Pd}$ components are more stiffer than $\mathrm{Ni}-\mathrm{Pd}$ alloys at high temperatures.

\begin{tabular}{|c|c|c|c|c|c|c|c|c|c|c|}
\hline Alloys & Temp. $[\mathrm{K}]$ & $C_{11}$ & $C_{12}$ & $C_{44}$ & $C_{111}$ & $C_{112}$ & $C_{123}$ & $C_{144}$ & $C_{166}$ & $C_{456}$ \\
\hline $\mathrm{Ni}_{50} \mathrm{Pd}_{50}$ & 100 & 1.917 & 1.361 & 0.606 & -19.569 & -13.084 & 0.819 & 1.330 & -6.107 & 0.420 \\
& 200 & 1.967 & 1.307 & 0.608 & -19.684 & -12.666 & 0.704 & 1.340 & -6.127 & 0.420 \\
& 300 & 2.026 & 1.254 & 0.611 & -19.854 & -12.239 & 0.590 & 1.350 & -6.150 & 0.420 \\
& 400 & 2.088 & 1.200 & 0.613 & -20.040 & -11.813 & 0.476 & 1.360 & -6.175 & 0.420 \\
& 500 & 2.151 & 1.147 & 0.616 & -20.234 & -11.388 & 0.361 & 1.370 & -6.201 & 0.420 \\
\hline $\mathrm{Ni}_{31} \mathrm{Pd}_{69}$ & 100 & 1.869 & 1.252 & 0.560 & -19.239 & -12.026 & 0.752 & 1.237 & -5.637 & 0.391 \\
& 200 & 1.915 & 1.200 & 0.562 & -19.336 & -11.614 & 0.637 & 1.246 & -5.654 & 0.391 \\
& 300 & 1.972 & 1.147 & 0.564 & -19.498 & -11.184 & 0.521 & 1.255 & -5.676 & 0.391 \\
& 400 & 2.033 & 1.094 & 0.566 & -19.680 & -10.755 & 0.405 & 1.265 & -5.699 & 0.391 \\
& 500 & 2.094 & 1.041 & 0.569 & -19.871 & -10.326 & 0.290 & 1.274 & -5.723 & 0.391 \\
\hline $\mathrm{Ni}_{21} \mathrm{Pd}_{79}$ & 100 & 1.852 & 1.199 & 0.537 & -19.110 & -11.503 & 0.720 & 1.192 & -5.413 & 0.376 \\
& 200 & 1.893 & 1.148 & 0.539 & -19.182 & -11.105 & 0.604 & 1.201 & -5.428 & 0.376 \\
& 300 & 1.948 & 1.095 & 0.541 & -19.331 & -10.675 & 0.487 & 1.209 & -5.448 & 0.376 \\
& 400 & 2.006 & 1.043 & 0.543 & -19.506 & -10.244 & 0.371 & 1.218 & -5.469 & 0.376 \\
& 500 & 2.067 & 0.990 & 0.546 & -19.692 & -9.813 & 0.255 & 1.227 & -5.492 & 0.376 \\
\hline \multirow{5}{*}{$\mathrm{Ni}_{6} \mathrm{Pd}_{94}$} & 100 & 1.882 & 1.116 & 0.508 & -19.235 & -10.613 & 0.666 & 1.131 & -5.123 & 0.356 \\
& 200 & 1.901 & 1.075 & 0.509 & -19.210 & -10.370 & 0.557 & 1.137 & -5.128 & 0.356 \\
& 300 & 1.941 & 1.025 & 0.511 & -19.277 & -9.970 & 0.441 & 1.145 & -5.142 & 0.356 \\
& 400 & 1.991 & 0.973 & 0.512 & -19.399 & -9.543 & 0.323 & 1.154 & -5.159 & 0.356 \\
& 500 & 2.045 & 0.921 & 0.514 & -19.551 & -9.111 & 0.206 & 1.162 & -5.178 & 0.356 \\
\hline
\end{tabular}

Table 1. Second and Third order elastic constans (SOEC \& TOEC) in $10^{11} \mathrm{~N} / \mathrm{m}^{2}$ of the Ni-Pd metallic alloys at temperature $100-500 \mathrm{~K}$.

\begin{tabular}{|l|c|c|c|c|c|c|c|c|c|}
\hline SOEC/TOEC $\rightarrow$ & $C_{11}$ & $C_{12}$ & $C_{44}$ & $C_{111}$ & $C_{112}$ & $C_{123}$ & $C_{144}$ & $C_{166}$ & $C_{456}$ \\
Metall/Alloy $\downarrow$ & & & & & & & & \\
\hline $\mathrm{Ni}$ (a) (exp.) & 2.500 & 1.510 & 1.220 & -21.04 & -13.45 & 0.59 & -3.80 & -7.57 & -0.42 \\
$\mathrm{Pd}(\mathrm{b})$ & 2.2378 & 1.7312 & 0.7125 & & & & & & \\
$\mathrm{Ni}_{0.55} \mathrm{Pd}_{0.45}$ (c) & 2.245 & 1.943 & 0.748 & & & & & & \\
\hline
\end{tabular}

(a) Work of V. P. N. Sharma et al. [20]; (b) Work of M. Kass et al. [23]; (c) Work of S. C. Upadhyaya et al. [18].

Table 2. Second and third order elastic constans (SOEC \& TOEC) in $10^{11} \mathrm{~N} / \mathrm{m}^{2}$ at $300 \mathrm{~K}$ for Ni and Pd metals and Ni-Pd alloy. 


\begin{tabular}{|c|c|c|c|c|c|}
\hline Metal & $\left(\alpha / f^{2}\right)_{\text {Akh.long }}$ & $\left(\alpha / f^{2}\right)_{\text {Akh.Shear }}$ & $\left(\alpha / f^{2}\right)_{\mathrm{Th} .}$ & $\left(\alpha / f^{2}\right)_{\text {Expt. }}$ & $\tau_{\text {th }\left(\times 10^{-12} \mathrm{sec}\right)}$ \\
\hline $\mathrm{Ni}(\mathrm{d})$ & 3.005 & 3.005 & 0.368 & $3.799(\mathrm{e})$ & 3.300 \\
\hline
\end{tabular}

(a) Work of V. P. N. Sharma et al. [20]; (e) Work of W. P. Messon [24].

Table 3. Ultrasonic attenuation $\left(\alpha / f^{2}\right)$ for longitudinal and sheer acoustic waves, thermoelastic attenuation $\left(\alpha / f^{2}\right)$ Th. along $\langle 100\rangle$ in $10^{-17} \mathrm{NpS}^{2} / \mathrm{m}$ and thermal relaxation time $\left(\tau_{\text {th }}\right)$ for $\mathrm{Ni}$ at $300 \mathrm{~K}$.

The ratio of longitudinal ultrasonic velocity to sheer wave velocity at $300 \mathrm{~K}$ for $\mathrm{Pd}$ becomes 1.527 [19] and 1.434 that for $\mathrm{Ni}$ at $300 \mathrm{~K}[12]$. For $\mathrm{Ni}_{50} \mathrm{Pd}_{50}$ alloys at $300 \mathrm{~K}$ this ratio becomes 1.676 . Thus the order of ratio of longitudinal to sheer wave velocity for $\mathrm{Ni}-\mathrm{Pd}$ alloys remains the same as pure components.

Thermal relaxation time $\left(\tau_{\mathrm{th}}\right)$ is also an important acoustical parameter, which affects the ultrasonic absorption in the materials. It is obvious from Fig. 3 and Table 3 that the present values of thermal relaxation time for $\mathrm{Ni}-\mathrm{Pd}$ alloys are greater in comparison with that of pure components. Due to these greater values, the ultrasonic absorption in $\mathrm{Ni}-\mathrm{Pd}$ alloys is expected to be greater than the pure components (Eq. 3). At room temperature, it is clear from Figs. $6-8$ and Table 3 that the ultrasonic absorption $\left(\alpha / f^{2}\right)$ is greater for $\mathrm{Ni}-\mathrm{Pd}$ alloys in comparison the those of $\mathrm{Ni}$ pure metal. These greater values of $\left(\alpha / f^{2}\right)$ for the alloys also support some disordering in the alloys as discussed earlier. Ultrasonic absorption $\left(\alpha / f^{2}\right)$ in $\mathrm{Ni}-\mathrm{Pd}$ alloys along $\langle 100\rangle$ increases with temperature (Figs. 6-8). This behaviour implies that disordering in $\mathrm{Ni}-\mathrm{Pd}$ alloys increases with temperature. However, the trend of temperature dependence of the ultrasonic absorption along $\langle 100\rangle$ in the alloys at high temperatures is the same as found in pure components. Ultrasonic absorption $\left(\alpha / f^{2}\right)$ in these alloys in every case becomes maximum at $500 \mathrm{~K}$. We conclude the investigation with the following important observations:

The theory for calculation of second and third order elastic constants of $\mathrm{Ni}$ and $\mathrm{Pd}$ seems to be valid for the $\mathrm{Ni}-\mathrm{Pd}$ alloys at high temperatures.

Pure components of $\mathrm{Ni}$ and $\mathrm{Pd}$ metals are stiffer than the $\mathrm{Ni}-\mathrm{Pd}$ alloys at high temperatures.

Resistivity values of pure components and $\mathrm{Ni}-\mathrm{Pd}$ alloys are important to explain disordering.

Behaviour of the ultrasonic absorption $\left(\alpha / f^{2}\right)$ in $\mathrm{Ni}-$ $\mathrm{Pd}$ alloys at high temperatures reveals some disordering in the alloys and this disordering increases with temperature.

Temperature dependence of the ultrasonic absorption in $\mathrm{Ni}-\mathrm{Pd}$ alloys at high temperatures has a similar trend as in the case of pure components.

The present theory of ultrasonic absorption which was originally formulated for pure metals seems to be valid for these alloys.

The concentration of components in the alloys may be estimated by the concentration variation of the ultrasonic absorption.
[1] A. K. Holmes, R. E. Challis, D. J. Wedlock, J. Colloid Interface Sci. 168, 339 (1994).

[2] V. I. Mazgovoi, A. M. Petchenko, A. F. Sirenko, Sov. Phys. Acoust. 36, 55 (1990).

[3] D. P. Singh, A. Kumar, J. Pure Appl. Ultras. 12, 9 (1990).

[4] G. A. Saunders, H. B. Senim, H. A. A. Sidek, Phys. Rev. B 48, 15801 (1993).

[5] A. Akhieser, J. Phys. (Moscow) 1, 277 (1939).

[6] W. P. Mason, H. J. Macskimin, J. Acoust. Soc. Am. 19, 464 (1947).

[7] W. P. Mason, J. Acoust. Soc. Am. 32, 458 (1960).

[8] T. O. Woodruff, H. I. Ehrenreich, Phys. Rev. 123, 1553 (1961).

[9] R. Nava, J. Romero, J. Acoust. Soc. Am. 64, 529 (1978).

[10] H. H. Barrett, M. G. Holland, Phys. Rev. B 1, 2538 (1970).

[11] S. K. Kor, G. Pandey, D. Singh, Acta Acustica united with Acustica 89, 105 (2003).

[12] K. Shankar, Ph. D. Thesis, Allahabad University, India (1981).

[13] R. R. Yadav, S. K. Kor, J. Acoust. Soc. India 17, 180
(1989).

[14] R. R. Yadav, D. Singh, J. Phys. Soc. Jpn. 70, 1825 (2001).

[15] A. Goldsmith, T. E. Waterman, H. J. Hirschhorn, Handbook of Thermophysical properties of Solids, II, (The Macmillan Company, New York, 1961).

[16] C. Kittel, Introduction to Solid State Physics (John Wiley Press, New York, 1981).

[17] D. E. Gray, Handbook of American Institute of Physics, (Mc-Graw Hill book company, New York,1963).

[18] S. C. Upadhyaya, J. C. Upadhyaya, R. Shyam, Phys. Rev. B 44, 122 (1991).

[19] D. K. Hsu, R. G. Leisure, Phys. Rev. B 20, 1339 (1979).

[20] V. P. N. Sharma, P. J. Reddy, Phil. Mag. 27, 769 (1973).

[21] D. S. Puri, M. P. Verma, Solid State Commun. 18, 1295 (1976).

[22] R. L. Fleischer, R. S. Gilmare, R. J. Zabala, Act Metall. 37, 2801 (1989).

[23] M. Kass, C. R. Brooks, D. Falcon, D. Basak, Intermetallics 10, 951 (2002).

[24] W. P. Mason, Phys. Acoustics and properties of solids (Van Nostrand, Princeton, 1958). 
R. R. YADAV, A. K. GUPTA, D. SINGH

\title{
НАДЗВУКОВЕ РОЗСІЮВАННЯ У СПЛАВАХ Ni-Pd У ВИСОКОТЕМПЕРАТУРНІЙ ФАЗІ
}

\author{
Р. Р. Ядав, А. К. Гупта, Д. Сінгх
}

Фізичний факультет, Аллахабадсъкий університет, Аллахабад-211002, Індія

Обчислено коефіцієнти надзвукового розсіювання фонон-фононної взаємодії та термоеластичний механізм у сплавах $\mathrm{Ni}-\mathrm{Pd}$ при 100-500 K вздовж напрямку $\langle 100\rangle$.

Обчислено також еластичні константи другого та третього порядку (SOEC i TOEC відповідно), числа Грюнайзена та надзвукові швидкості. Використовуючи ці параметри, визначено надзвукове розсіювання. Знайдено, що метали $\mathrm{Ni}$ i $\mathrm{Pd} є$ жорсткішими, ніж сплави $\mathrm{Ni}-\mathrm{Pd}$. Поведінка надзвукового розсіювання при високих температурах указує на деяку невпорядкованість у сплавах. 